\title{
Aortic root replacement, the "gold" standard: All that shines is not gold!
}

\author{
Joseph S. Coselli, MD
}

\footnotetext{
From the Division of Cardiothoracic Surgery, Michael E. DeBakey Department of Surgery, Baylor College of Medicine; the Department of Cardiovascular Surgery, Texas Heart Institute; and CHI St Luke's Health-Baylor St Luke's Medical Center, Houston, Tex.

Disclosures: J.S.C. serves as principle investigator for clinical trials conducted by Edwards Lifesciences and Medtronic, Inc, and as a consultant for Vascutek Ltd, a Terumo Company, and Medtronic, Inc.

Received for publication June 29, 2016; accepted for publication June 30, 2016; available ahead of print Aug 16, 2016.

Address for reprints: Joseph S. Coselli, MD, One Baylor Plaza, BCM 390, Houston, TX 77030 (E-mail: jcoselli@ bcm.edu).

J Thorac Cardiovasc Surg 2016;152:956-7

$0022-5223 / \$ 36.00$

Copyright (c) 2016 by The American Association for Thoracic Surgery

http://dx.doi.org/10.1016/j.jtcvs.2016.06.056
}

In this issue of the Journal, Di Marco and colleagues ${ }^{1}$ report on a remarkable series of patients undergoing composite valve graft $(\mathrm{CVG})$ replacement for aortic valve and root pathology. Their experience spans 33 years (1978-2010) and analyzes the results of 1045 patients. The classic Bentall operation $^{2}$ was used in 95 patients $(9.1 \%)$, whereas modified Bentall operations were performed in 24 patients $(2.3 \%)$ with the Cabrol coronary artery graft interposition technique $^{3}$ and in 926 patients $(88.6 \%)$ with the Kouchoukos coronary artery button reattachment technique. ${ }^{4} \mathrm{~A}$ mechanical CVG was used in 727 cases $(69.6 \%$ ), whereas a biologic CVG was used in 318 (30.4\%). Only 55 patients $(5.3 \%)$ had Marfan syndrome, 127 patients (12.1\%) underwent reoperation, and 930 repairs were performed electively $(89 \%)$. The early results were excellent, with an operative mortality of 5.3\% (55 of 1045 patients).

An important contribution by Di Marco and colleagues ${ }^{1}$ is their extensive long-term follow-up. Despite a cohort of patients extending across 3 decades, nearly all early survivors (966 of 990 hospital survivors; 97.6\%) were available for follow-up, although the mean follow-up time was a modest $62.1 \pm 58.6$ months. There were 164 late deaths $(16.6 \%)$, and most were the result of tumor, sudden cardiac death, or stroke. Di Marco and colleagues ${ }^{1}$ convincingly point out that patients with aortic dissection had a lower long-term survival than did those without aortic dissection (27.2\% vs $43.3 \%$ at 20 years of follow-up). With respect to clinical events at 20 years, $90.1 \%$ of early survivors remained free of thromboembolic events, 98.4\% were free of endocarditis, 90.3\% were free of hemorrhagic events, and $91.3 \%$ were free of any further aortic reoperation.

Although Di Marco and colleagues ${ }^{1}$ report only a small number of patients with Marfan syndrome $(5.3 \%$, most of whom received a mechanical $\mathrm{CVG}$ ), they allude to concerns with aortic valve-sparing approaches to aortic root replacement ${ }^{5}$ and refer to a small study conducted by Fleischer and associates, ${ }^{6}$ who found histologic

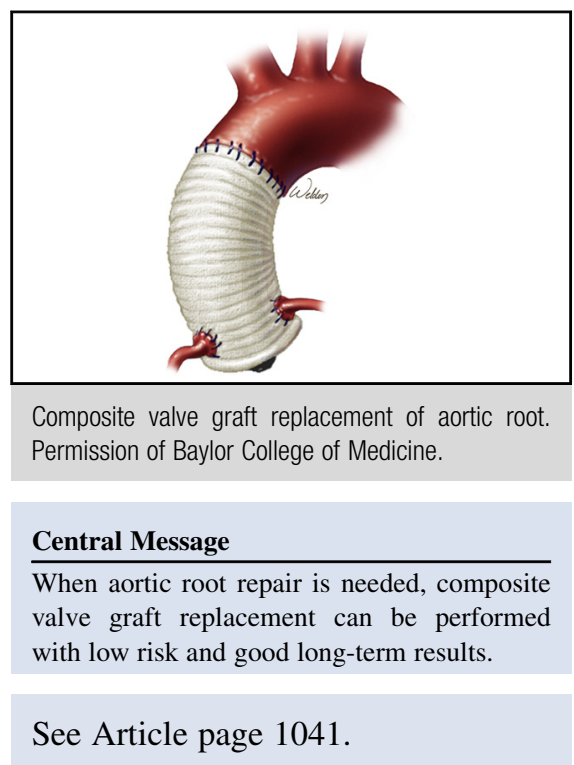

abnormalities in the aortic valves of patients with Marfan syndrome, as justification for their avoidance of valve-sparing techniques in such patients. Because their experience ends in 2010, however, and most experienced institutions have shifted to valve-sparing approaches in such patients, it would be reasonable to presume that their contemporary use of valve-sparing techniques has very likely increased. An example detailing this shift would be Price and coworkers, because their group evaluated 165 adult patients with Marfan syndrome, including 98 patients who underwent valve-sparing repair and 67 patients who underwent a modified Bentall operation. They demonstrated that both procedures could both be done quite safely and with similar late survivals, freedoms from root reoperation, and freedoms from endocarditis; however, Price and coworkers ${ }^{7}$ point out that valve-sparing procedures resulted in significantly fewer thromboembolic and hemorrhagic events, having spared those patients from long-term anticoagulation.

In summary, in this issue of the Journal, Price and coworkers, ${ }^{7}$ report one of the largest series detailing CVG replacement of the aortic valve and root disease. Their outstanding results, excellent follow-up, and durability of repair provide a backdrop against which valve-sparing techniques, as well as other surgical alternatives to aortic root repair, can be compared for decades to come.

\section{References}

1. Di Marco L, Pacini D, Pantaleo A, Leone A, Barberio G, Marinelli G, et al. Composite valve graft implantation for the treatment of aortic valve and root 
disease: Results in 1045 patients. J Thorac Cardiovasc Surg. 2016;152: 1041-8.e1.

2. Bentall H, De Bono A. A technique for complete replacement of the ascending aorta. Thorax. 1968;23:338-9.

3. Cabrol C, Gandjbakhc I, Pavie A. Surgical treatment of ascending aortic pathology. J Card Surg. 1988:3:167-80.

4. Kouchoukos NT, Wareing TH, Murphy SF, Perrillo JB. Sixteen-year experience with aortic root replacement. Results of 172 operations. Ann Surg. 1991;214: 308-18; discussion 318-20.
5. David TE, Feindel CM. An aortic valve-sparing operation for patients with aortic incompetence and aneurysm of the ascending aorta. J Thorac Cardiovasc Surg. 1992;103:617-21; discussion 622.

6. Fleischer KJ, Nousari HC, Anhalt GJ, Stone CD, Laschinger JC. Immunohistochemical abnormalities of fibrillin in cardiovascular tissues in Marfan's syndrome. Ann Thorac Surg. 1997;63:1012-7.

7. Price J, Magruder JT, Young A, Grimm JC, Patel ND, Alejo D, et al. Long-term outcomes of aortic root operations for Marfan syndrome: a comparison of Bentall versus aortic valve-sparing procedures. J Thorac Cardiovasc Surg. 2016; 151:330-6.

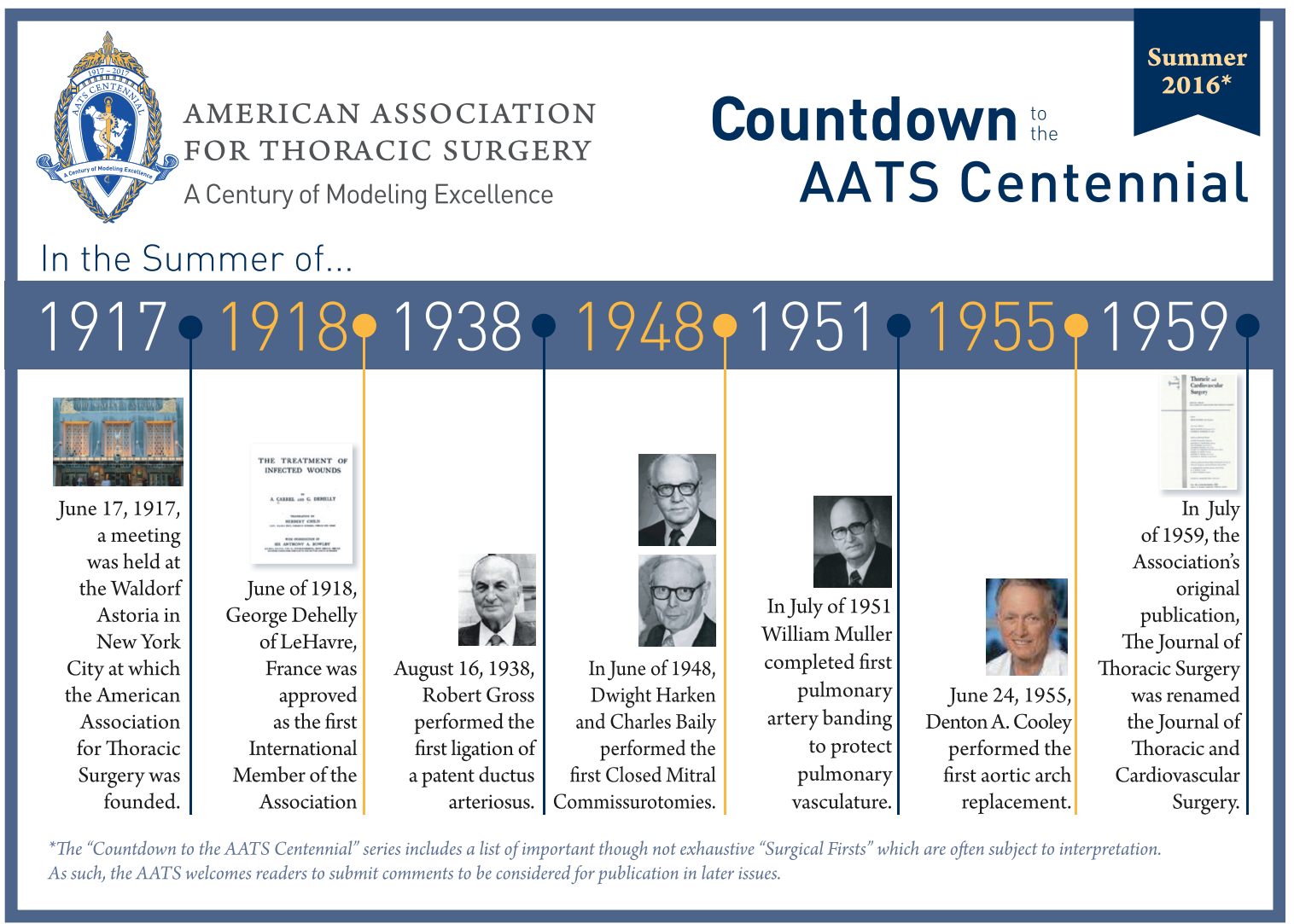

